\title{
Creation of a second submucosal tunnel enabled successful per-oral endoscopic myotomy (POEM)
}

\author{
Madhusudhan R. Sanaka, MD, ${ }^{a}$ Prashanthi N. Thota, MD, ${ }^{a}$ Sudish C. Murthy, MD, PhD, ${ }^{\mathrm{b}}$ and \\ Siva Raja, MD, PhD, ${ }^{\mathrm{b}}$ Cleveland, Ohio
}

\author{
From the Departments of ${ }^{\mathrm{a}}$ Gastroenterology and ${ }^{\mathrm{b}}$ Thoracic Surgery, Cleveland Clinic, Cleveland, Ohio \\ Presented in abstract form at Digestive Disease Week, Washington, DC, May 2015. \\ Disclosures: Authors have nothing to disclose with regard to commercial support. \\ Received for publication Feb 16, 2015; revisions received Dec 15, 2015; accepted for publication Jan 20, 2016; \\ available ahead of print March 3, 2016. \\ Address for reprints: Madhusudhan R. Sanaka, MD, Department of Gastroenterology/Hepatology, Q3 Cleveland \\ Clinic, 9500 Euclid Ave, Cleveland, OH 44195 (E-mail: sanakam@ccf.org). \\ J Thorac Cardiovasc Surg 2016;151:e101-2 \\ $0022-5223 / \$ 36.00$ \\ Copyright $(2016$ by The American Association for Thoracic Surgery \\ http://dx.doi.org/10.1016/j.jtcvs.2016.01.047
}

Heller myotomy with partial fundoplication has emerged as a preferred and durable treatment option for palliation of symptoms in achalasia. However, approximately $10 \%$ to $20 \%$ of patients have recurrent symptoms on longterm follow-up. ${ }^{1}$ This is due to inadequate myotomy, fibrosis at myotomy, or progression of the disease. Treatment options for recurrent symptoms after Heller myotomy include redo surgical myotomy, pneumatic dilation, or recently evolving per-oral endoscopic myotomy (POEM). ${ }^{1-4}$ Standard steps of POEM include a 2-cm mucosotomy in the mid esophagus, creation of submucosal tunnel extending 2 to $4 \mathrm{~cm}$ onto the gastric wall, division of the inner circular muscle of the most distal 5 to $6 \mathrm{~cm}$ of esophagus and extending 2 to $4 \mathrm{~cm}$ into the stomach wall, and closure of the mucosotomy with endoscopic clips. ${ }^{5}$ Previous treatment for achalasia, such as Botulinum toxin injection, pneumatic dilation, or Heller myotomy, might pose a technical challenge for performing POEM due to submucosal fibrosis. We present one such case in which POEM was successful by creation of a second submucosal tunnel.

\section{CASE}

A 62-year-old man had recurrent symptoms of achalasia including dysphagia, regurgitation, and weight loss with an Eckardt score of 5 (range 0-12 with higher score indicating more severe symptoms) after a Heller myotomy via thoracotomy more than 25 years ago. A timed barium esophagram showed sigmoid esophagus, tight gastroesophageal junction (GEJ), and delayed emptying of the contrast with height and width of residual barium column 3.5 and $4.0 \mathrm{~cm}$, respectively, at 5 minutes. High-resolution esophageal manometry was consistent with type I achalasia. We elected POEM for palliation of symptoms, with creation of mucosotomy on the right lateral wall of the mid esophagus due to previous Heller myotomy on the left lateral

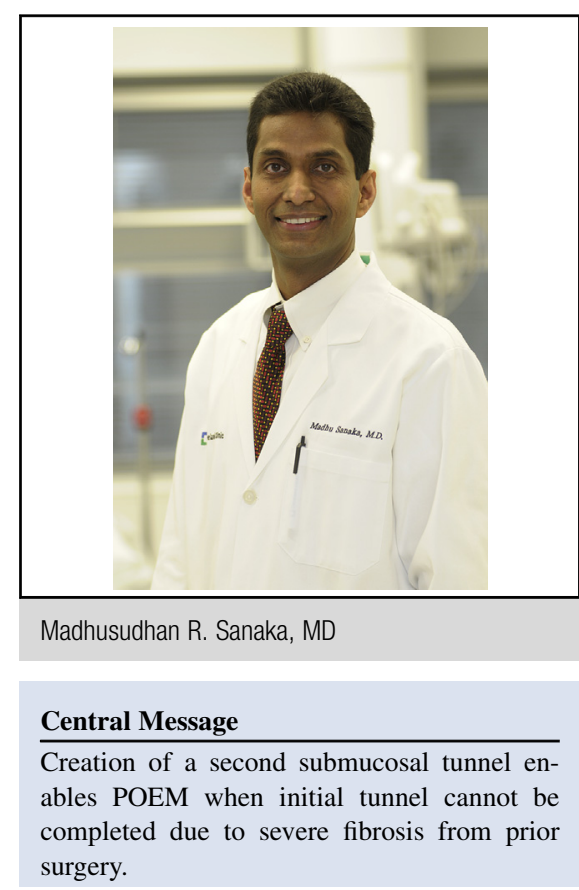

See Editorial Commentary page e103.

wall. During submucosal tunneling, we encountered severe fibrosis and obliteration of submucosal space in the lower esophagus, precluding further tunneling. We elected to create a second tunnel on the posterior esophageal wall starting approximately $2 \mathrm{~cm}$ distal to the initial mucosotomy site. The second tunnel was successfully extended onto the gastric side and POEM was successful without complications. The patient had significant improvement of symptoms at 2-month follow-up with an Eckardt score of 0 .

\section{DISCUSSION}

This case describes creation of a second submucosal tunnel to enable successful POEM. Previous treatment for achalasia, such as Botulinum toxin injection, pneumatic dilation, or Heller myotomy might pose a technical challenge for performing POEM due to submucosal fibrosis. Because our patient had a previous myotomy via thoracotomy rather than laparoscopy, it is possible that the initial operative approach led to more pronounced submucosal fibrosis. This precluded extension of submucosal tunnel 
during POEM. Our case demonstrates a practical solution in such situations, and we suggest POEM operators to consider this option when they encounter severe fibrosis precluding tunnel creation during POEM.

\section{References}

1. Zaninotto G, Costantini M, Portale G, Battaglia G, Molena D, Carta A, et al. Etiology, diagnosis, and treatment of failures after laparoscopic Heller myotomy for achalasia. Ann Surg. 2002;235:186-92.
2. Guardino JM, Vela MF, Connor JT, Richter JE. Pneumatic dilation for the treat ment of achalasia in untreated patients and patients with failed Heller myotomy J Clin Gastroenterol. 2004;38:855-60.

3. Vigneswaran Y, Yetasook AK, Zhao JC, Deham W, Linn JG, Ujiki MB. Peroral endoscopic myotomy (POEM): feasible as reoperation following Heller myotomy. J Gastrointest Surg. 2014;18:1071-6.

4. Zhou PH, Li QL, Yao LQ, Xu MD, Chen WF, Cai MY, et al. Peroral endoscopic remyotomy for failed Heller myotomy: a prospective single-center study. Endoscopy. 2013;45:161-6.

5. Inoue H, Minami H, Kobayashi Y, Sato Y, Kaga M, Suzuki M, et al. Peroral endoscopic myotomy (POEM) for esophageal achalasia. Endoscopy. 2010;42:265-71. 